\title{
Association between plasma concentration of tolvaptan and urine volume in acute decompensated heart failure patients with fluid overload
}

\author{
Mahoto Kato, Kazuto Tohyama, Toshiyuki Ohya, Takafumi Hiro, Atsushi Hirayama \\ Division of Cardiovascular Medicine, Nihon University Itabashi Hospital, \\ Nihon University School of Medicine, Tokyo, Japan
}

\begin{abstract}
Background: Tolvaptan (TLV) is a useful diuretic for acute decompensated heart failure (ADHF) with fluid overload, but its clinical response varies between patients. The aim of this study is to investigate whether plasma TLV concentrations correlate with the urine volume.

Methods: ADHF inpatients with evidence of fluid overload and total urine volume $<1,500 \mathrm{~mL}$ $24 \mathrm{~h}$ after initial intravenous administration of $40 \mathrm{mg}$ furosemide were included in the study. On days 1-7, $7.5 \mathrm{mg}$ oral TLV was added. The plasma TLV concentration, plasma renin activity (PRA), and plasma aldosterone concentration (PAC) were measured on days 1, 3 and 7.

Results: In the 52 patients who completed the protocol, the TLV concentration increased significantly from $67.6 \pm 30.1 \mathrm{ng} / \mathrm{mL}$ on day 1 to $98.3 \pm 39.6 \mathrm{ng} / \mathrm{mL}$ on day 3 to $144.8 \pm$ $\pm 44.2 \mathrm{ng} / \mathrm{mL}$ on day 7 , and the TLV concentration correlated with total urine volume on days 3 and 7 ( $r=0.392, p<0.01 ; r=0.639, p<0.001$, respectively) but not on day 1 . The urine volume correlated inversely with PRA and PAC $(r=-0.618, p<0.05 ; r=-0.547$, $p<0.05$, respectively).
\end{abstract}

Conclusions: Plasma TLV concentrations correlated with the urine volume in late phase of treatment but not in early phase, which suggests that the effect of TLV may possibly be inhibited by renin-angiotensin-aldosterone system activity. (Cardiol J 2016; 23, 5: 497-504)

Key words: tolvaptan, selective vasopressin type 2 receptor antagonist, plasma concentration, renin-angiotensin-aldosterone system, acute decompensated heart failure

\section{Introduction}

Tolvaptan (TLV), a selective V2-vasopressin receptor antagonist, is known for its excellent diuretic effect, and in Japan, it has been essential for intensive treatment of patients hospitalized for acute decompensated heart failure (ADHF) with fluid overload [1-9]. Since its approval for clinical use, we have noticed that the response to TLV varies from patient to patient, and the mechanism of

Address for correspondence: Dr Mahoto Kato, Division of Cardiovascular Medicine, Nihon University Itabashi Hospital, Nihon University School of Medicine, 30-1 Ohyaguchi Kamicho, Itabashiku, Tokyo, Japan, tel: +81-3-3972-8111, fax: +81-3-3972-1098, e-mail: mahotok@gmail.com 
action has been discussed, which may be affected by renal function, anemia and low cardiac output. However, TLV is an oral drug and thus might be affected by intestinal absorption, and heart failure patients for whom this oral drug is indicated usually have fluid overload and digestive system swelling. What follows, differences in patients' absorption of TLV might be responsible for differences in the clinical response to TLV, even though the dosages and patients' medical conditions are the same. When we discuss the clinical responses to TLV, we must understand the relation between a patient's plasma TLV concentration and patient's clinical response. However, to our knowledge, this question has been explored in only a few patients with $\mathrm{ADHF}$ and fluid overload [10]. Thus, the purpose of the present study was to determine whether the plasma concentration of TLV differs between the early phase of treatment and the late phase, and whether the plasma TLV concentration is associated with urine volume in ADHF patients with evidence of fluid overload.

\section{Methods}

\section{Patients}

Consecutive patients who were admitted to our hospital between April 1, 2014 and March 31, 2015 for worsening congestive heart failure requiring intensive treatment were screened for participation in our study. Patients considered eligible for the study were men and women over 20 years of age with evidence of fluid overload at the time of screening, having orthopnea and edema of the extremities and jugular venous distention defined as jugular venous pressure (JVP) $>10 \mathrm{~cm} \mathrm{H}_{2} \mathrm{O}$, and at least rales at the base of the lungs (Killip class 2 or 3). We excluded patients with acute myocardial infarction at the time of admission; patients using any inotropic agent, cardiac mechanical support and/or ventilation including non-invasive positive pressure ventilation; patients on hemofiltration or dialysis; those with pulmonary hypertension due to pre-capillary occlusion; those with systolic blood pressure $<100 \mathrm{~mm} \mathrm{Hg}$ upon admission; those with an estimated glomerular filtration rate (eGFR) $<60 \mathrm{~mL} / \mathrm{min} / 1.73 \mathrm{~m}^{2}$; those with hemoglobin $<10.0 \mathrm{~g} / \mathrm{mL}$ or a serum sodium concentration $>146 \mathrm{mEq} / \mathrm{L}$; and those from whom we did not obtain informed consent.

\section{Study design}

Patients were screened within $6 \mathrm{~h}$ of hospitalization, and eligible patients were given $40 \mathrm{mg}$ furo-

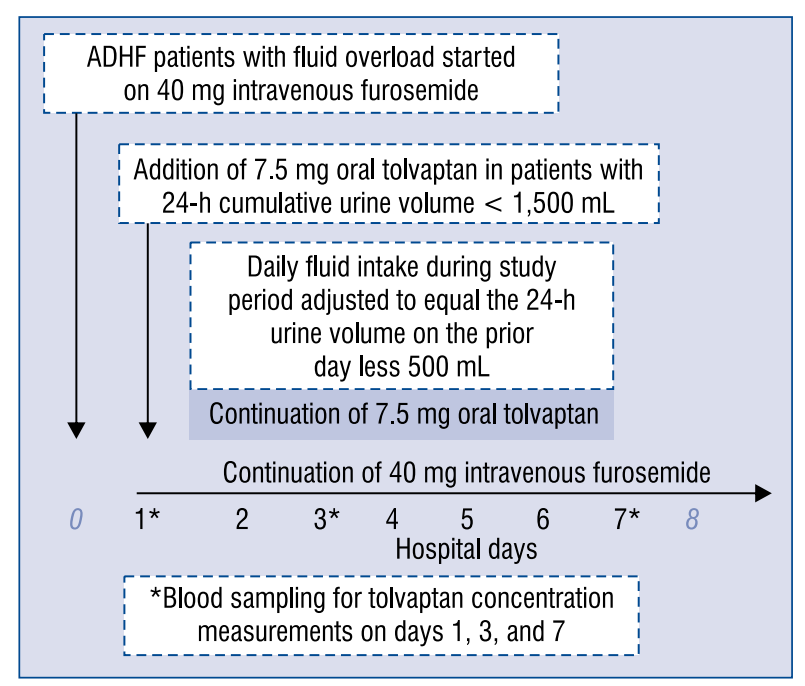

Figure 1. Schematic representation of the study protocol; ADHF - acute decompensated heart failure.

semide intravenously until the first morning (day 0 ). Patients whose 24-h cumulative urine volume was $>1,500 \mathrm{~mL}$ were excluded. For patients not excluded, $7.5 \mathrm{mg}$ TLV was added to the $40 \mathrm{mg}$ furosemide starting on the next morning (day 1 ) and continuing for 7 days (from day 1 to day 7) (Fig. 1). Oral medications which the patients had been taking before hospitalization, including digoxin, any angiotensin-converting enzyme inhibitor, angiotensin II receptor blocker, beta-blocker, and nitrate, were continued for at least 7 days at the discretion of the attending physician. Patients treated with any inotropic agent or carperitide (recombinant human natriuretic peptide) and any diuretic, except intravenous furosemide, were excluded for the duration of the study. During the TLV administration period, total daily fluid intake was adjusted to equal the 24 -h urine volume on the prior day minus $500 \mathrm{~mL}$.Patients whose symptoms or signs of fluid overload disappeared in fewer 7 days are dropped from this protocol.

Patients' symptoms, graded on a visual analog scale from 0 (worst ever) to 10 (no symptoms); extremity edema, graded as 0 (none) to 4 (severe); jugular venous distention, hepatomegaly and/or hepatojugular reflux were assessed daily by patients' attending physicians after blood sampling. Blood samples for measurement of plasma renin activity (PRA), plasma aldosterone concentration (PAC) and blood concentration of noradrenaline were drawn at 8:00 AM on days 1, 3 and 7, and patients were required to rest supine on a bed for $30 \mathrm{~min}$ before samples were drawn. Samples were 
drawn for the plasma TLV concentration exactly $4 \mathrm{~h}$ after oral administration of TLV. Blood samples were collected in heparinized vacuum tubes, gently mixed, and then immediately centrifuged at $4^{\circ} \mathrm{C}$ for $15 \mathrm{~min}$ at 2,000 $\mathrm{g}$ for plasma separation. The plasma was stored at $-20^{\circ} \mathrm{C}$ or below until assay. The plasma TLV concentration was determined by means of a validated high-performance liquid chromatography tandem mass spectrometry method at Toray Research Center, Inc. Details have been described previously [11]. The safety of TLV administration in each case was based on an assessment of the patient's physical signs and symptoms, laboratory tests, and vital signs. The study protocol was stopped if a patient's attending physician advised accordingly. This study was approved by the institutional review board and Ethics Committee of Nihon University Itabashi Hospital, and it was conducted in accordance with the principals outlined in the Declaration of Helsinki. Written informed consent was obtained from all participants.

\section{Statistical analysis}

Continuous variables are expressed as mean \pm standard deviation (SD), and categorical variables as median [Q1-Q3] values or number (percentage) of patients. Differences in continuous variables were analyzed by means of paired Student's t-test, and differences in categorical variables were analyzed by $\chi^{2}$ test. Relations between variables were assessed by Pearson's product-moment correlation coefficient. All statistical analyses were carried out with SAS (version 9.0; SAS Institute Inc, Cary, NC), and $\mathrm{p}<0.05$ was considered statistically significant.

\section{Results}

\section{Patient characteristics}

Two hundred eighty-six patients met the initial inclusion criteria and were given $40 \mathrm{mg}$ furosemide intravenously until the first morning (day 0). Ninety-two patients with a cumulative 24-h urine volume of less than $1,500 \mathrm{~mL}$ after the administration of furosemide were given $7.5 \mathrm{mg}$ of oral TLV starting on day 1 . Forty patients were dropped from the study (36 patients in whom the symptoms fluid overload disappeared in fewer than 7 days and 4 patients in whom the serum sodium level increased to more than $146 \mathrm{mEq} / \mathrm{mL}$ ). Thus, 52 patients completed the study protocol (Fig. 2).

Mean age of the 52 patients who completed the protocol was $66.4 \pm 11.8$ years, the male/fe-

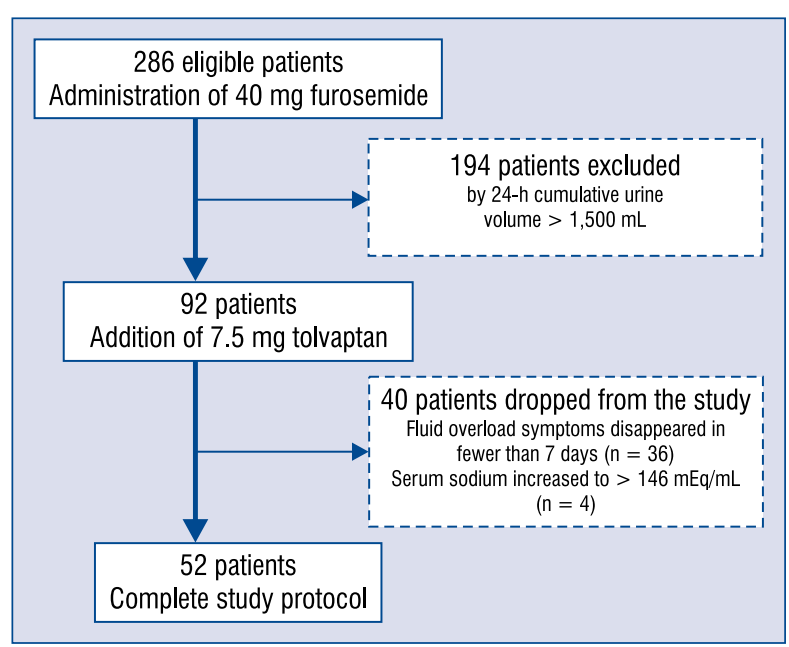

Figure 2. Flow diagram showing progress of enrollees through phases of the study.

male ratio was $31 / 21$, mean systolic blood pressure amounted to $121 \pm 15 \mathrm{~mm} \mathrm{Hg}$ and heart rate to $84 \pm 18$ bmp. Nine (17\%) patients had ischemic heart disease, and $6(12 \%)$ had atrial fibrillation. Forty-six (88\%) had been taking furosemide, and $26(50 \%)$ had been taking spironolactone. All patients had orthopnea, rales at the base of both lungs, edema of the extremities and jugular venous distension defined as JVP $>10 \mathrm{~cm} \mathrm{H}_{2} \mathrm{O}$. Mean left ventricular (LV) ejection fraction was $42.5 \pm$ $\pm 10.5 \%$, mean LV diastolic diameter was $63.7 \pm$ $\pm 10.5 \mathrm{~mm}$ and mean diameter of the inferior vena cava was $23.6 \pm 5.3 \mathrm{~mm}$, with reduced respiratory movement. The mean serum creatinine level was $1.12 \pm 0.27 \mathrm{mg} / \mathrm{mL}$, mean eGFR was $78.8 \pm 12.8 \mathrm{~mL} /$ $/ \mathrm{min} / 1.73 \mathrm{~m}^{2}$, mean N-terminal prohormone of B-type natriuretic peptide was 9,079 $\pm 7,795 \mathrm{pg} / \mathrm{mL}$ and mean urine osmolality was $477 \pm 167 \mathrm{mOsm} / \mathrm{L}$ (Table 1).

\section{Urine volume and body weight}

Urine volume increased from 1,066 $\pm 365 \mathrm{~mL}$ on day 0 to $2,760 \pm 956 \mathrm{~mL}$ on day 1 (Fig. 3), and body weight decreased steadily up to day 7 . The increase in urine volume and the decrease in body weight lessened after day 4 . After completion of the TLV regimen (day 8), the urine volume decreased significantly and body weight increased slightly in comparison to measurements on day 7 . Daily total fluid intakes were less than 24 -h urine volume minus $500 \mathrm{~mL}$ because some of the patients whose urine volume was more than $3,500 \mathrm{~mL} /$ day could not take enough fluid. 
Table 1. Patient characteristics upon enrollment.

\begin{tabular}{|c|c|}
\hline Age [years] & $66.4 \pm 11.8$ \\
\hline Male/female ratio & $31 / 21(60 \% / 40 \%)$ \\
\hline Bodyweight [kg] & $68.0 \pm 15.5$ \\
\hline Heart rate $[\mathrm{bpm}]$ & $84 \pm 18$ \\
\hline Systolic blood pressure [mm Hg] & $121 \pm 15$ \\
\hline Diastolic blood pressure $[\mathrm{mm} \mathrm{Hg}]$ & $70 \pm 9$ \\
\hline \multicolumn{2}{|l|}{ Etiology of HF: } \\
\hline Ischemic heart disease & $9(17 \%)$ \\
\hline Dilated cardiomyopathy & $19(37 \%)$ \\
\hline Valvular disease & $16(31 \%)$ \\
\hline Other & $8(15 \%)$ \\
\hline \multicolumn{2}{|l|}{ Medical history: } \\
\hline Atrial fibrillation & $6(12 \%)$ \\
\hline Hypertension & $11(21 \%)$ \\
\hline Dyslipidemia & $15(29 \%)$ \\
\hline Diabetes & $14(27 \%)$ \\
\hline \multicolumn{2}{|l|}{ Oral medications at admission: } \\
\hline Furosemide & $46(88 \%)$ \\
\hline Spironolactone & $26(50 \%)$ \\
\hline ACE-I & $31(60 \%)$ \\
\hline ARB & $20(38 \%)$ \\
\hline Beta-blocker & $36(70 \%)$ \\
\hline Digitalis & $13(25 \%)$ \\
\hline Calcium channel blocker & $15(29 \%)$ \\
\hline Statin & $9(17 \%)$ \\
\hline \multicolumn{2}{|c|}{ Symptoms and results of physical examination: } \\
\hline NYHA functional class, I-IV & III [III-III] \\
\hline Killip class, $0-4$ & $3[2-3]$ \\
\hline Extremity edema, $0-4 *$ & $3[2-4]$ \\
\hline Jugular venous pressure $\left[\mathrm{cm} \mathrm{H}_{2} \mathrm{O}\right]$ & $19.3 \pm 2.5$ \\
\hline \multicolumn{2}{|l|}{ Chest $\mathrm{X}$-ray findings: } \\
\hline Cardiothoracic ratio [\%] & $64 \pm 9$ \\
\hline Pleural effusion & $48(92 \%)$ \\
\hline \multicolumn{2}{|l|}{ Echocardiographic findings: } \\
\hline Left ventricular ejection fraction [\%] & $42.5 \pm 10.5$ \\
\hline Left ventricular diastolic diameter [mm] & $63.7 \pm 10.5$ \\
\hline Inferior vena cava [mm] & $23.6 \pm 5.3$ \\
\hline Moderate to severe MR & $17(33 \%)$ \\
\hline TRPG $[\mathrm{mm} \mathrm{Hg}]$ & $37.5 \pm 15.5$ \\
\hline \multicolumn{2}{|l|}{ Laboratory test results: } \\
\hline Serum creatinine $[\mathrm{mg} / \mathrm{mL}]$ & $1.12 \pm 0.27$ \\
\hline eGFR $\left[\mathrm{mL} / \mathrm{min} / 1.73 \mathrm{~m}^{2}\right]$ & $78.8 \pm 12.8$ \\
\hline Blood urea nitrogen $[\mathrm{mg} / \mathrm{mL}]$ & $28.0 \pm 11.8$ \\
\hline Serum sodium $[\mathrm{mEq} / \mathrm{L}]$ & $138.2 \pm 4.9$ \\
\hline Serum potassium $[\mathrm{mEq} / \mathrm{L}]$ & $4.2 \pm 0.7$ \\
\hline Total bilirubin [mg/mL] & $1.2 \pm 1.1$ \\
\hline NT-proBNP [pg/mL] & $9079 \pm 7795$ \\
\hline Urine osmolality [mOsm/L] & $477 \pm 167$ \\
\hline
\end{tabular}

${ }^{*} 0$ - none, 4 - severe; data are shown as mean \pm standard deviation (SD), $\mathrm{n}$ [\%] or median [Q1-Q3] values; ACE-I - angiotensin converting enzyme inhibitor; ARB - angiotensin receptor blocker; eGFR - estimated glomerular filtration rate; $\mathrm{HF}$ - heart failure; $\mathrm{MR}-$ mitral valve regurgitation; NT-proBNP $-\mathrm{N}$-terminal of the prohormone B-type natriuretic peptide; NYHA - New York Heart Association; TRPG - tricuspid regurgitation pressure gradient
Change in the plasma concentration of TLV (days 1-7)

The plasma TLV concentration increased from $67.6 \pm 30.1 \mathrm{ng} / \mathrm{mL}$ on day 1 to $98.3 \pm 39.6 \mathrm{ng} / \mathrm{mL}$ on day 3 ( $\mathrm{p}<0.01$ vs. day 1$)$ to $144.8 \pm 44.2 \mathrm{ng} / \mathrm{mL}$ on day 7 ( $\mathrm{p}<0.001 \mathrm{vs}$. day 1$)$, which was approximately twice the day-1 value (Fig. 4).

\section{Correlation between the urine volume and plasma concentration of TLV}

Although there was no relation between the urine volume and plasma TLV concentration and on day 1 (Fig. 5A), the urine volume correlated significantly with the plasma TLV concentration on days 3 and $7(\mathrm{r}=0.392, \mathrm{p}<0.01 ; \mathrm{r}=0.639$, $\mathrm{p}<0.001$, respectively) (Fig. 5B, C).

\section{Association between change in the urine volume and RAAS activity in the early phase of treatment}

Change in the urine volume on day 1 correlated inversely with $\mathrm{PRA}$ and $\mathrm{PAC}$, which are indicators of renin-angiotensin-aldosterone system (RAAS) activity, after administration of TLV $(\mathrm{r}=-0.618 ; \mathrm{p}<0.05, \mathrm{r}=-0.547 ; \mathrm{p}<0.05$, respectively) (Fig. 6A, B).

\section{Discussion}

Tolvaptan is an oral aquaretic drug that was recognized for insurance reimbursement by the Japanese Ministry of Health, Labor and Welfare in 2010. It has shown excellent clinical effects in ADHF patients with evidence of fluid overload, and it broadens our options for the treatment of $\mathrm{ADHF}$ as an addition to standard furosemide-based natriuretic therapy $[5-7,9,12,13]$. However, according to our experience, the clinical response to TLV varies between patients, and renal function, especially renal tubular function, has been reported to influence the effects of TLV in the kidney [14-16]. Imamura et al. [16] investigated the relation between urine osmolality and the increase in urine volume of patients treated with TLV and reported that the percent change in urine osmolality after administration of TLV can predict the clinical response.

However, we must also take into consideration absorption of the TLV by the digestive system. The digestive ducts are usually swollen because of systemic congestion arising from decompensated heart failure with fluid overload. In addition, these days, TLV is generally started as part of the early phase of treatment of ADHF with fluid overload 


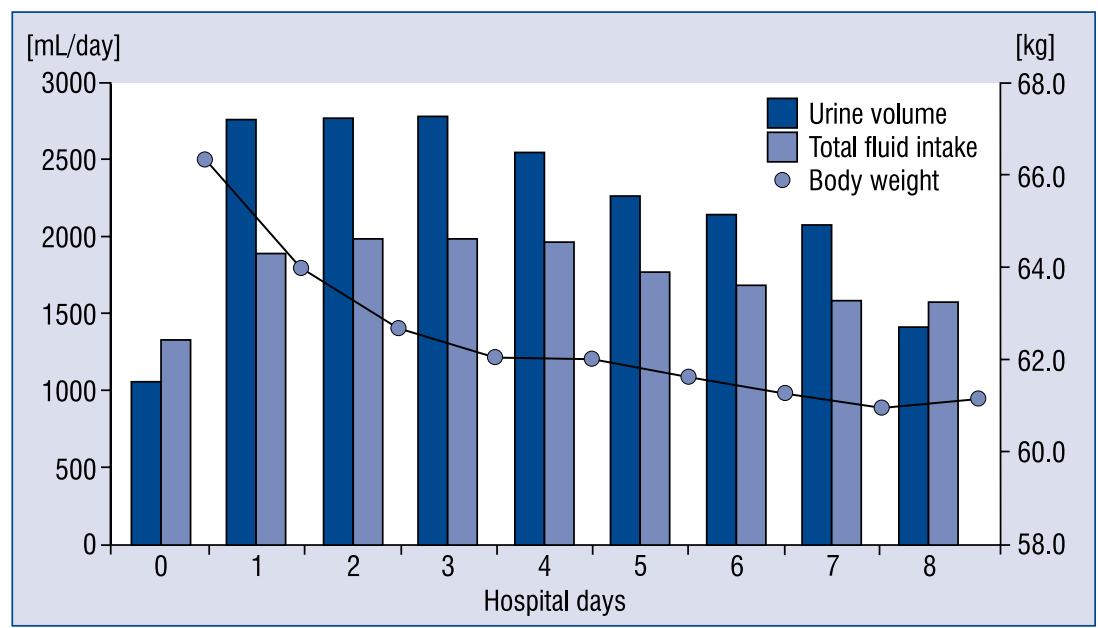

Figure 3. 24-h urine volume, total fluid intake and change in body weight over the course of the study (days 0-8). Note that values were based on the next day's measurements, e.g., 24-h urine volume shown for day 1 was actually determined in the morning of day 2. The graph clearly depicts the significant increase in urine volume and decrease in body weight after the addition of tolvaptan and that these clinical effects continued until the tolvaptan was stopped on day 7.

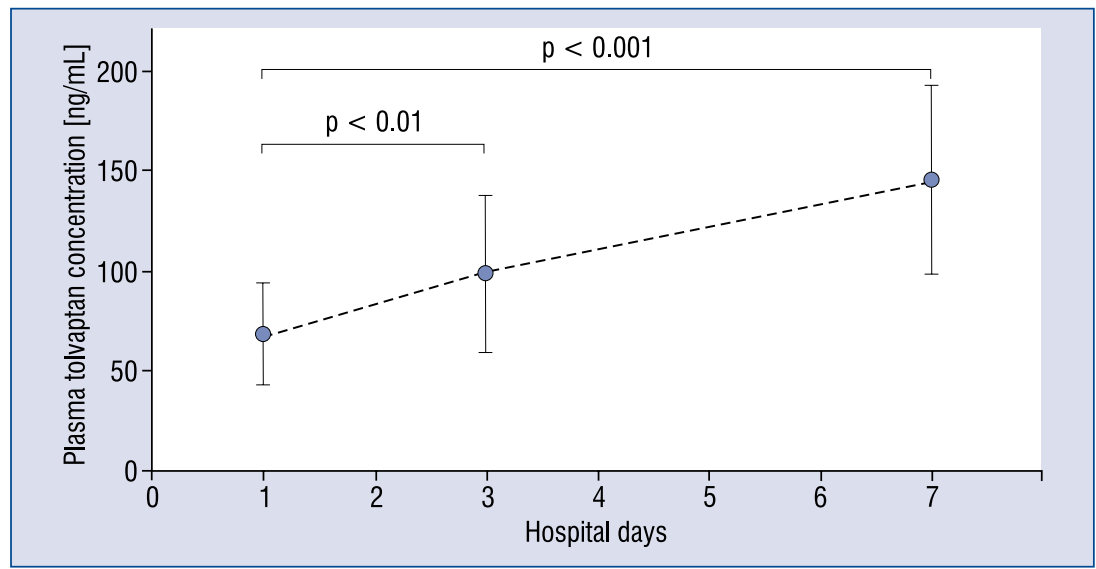

Figure 4. Change in the plasma tolvaptan concentration over days $0-7$. Note that the plasma tolvaptan concentration doubled by the end of the 7-day administration.

rather than the late phase of treatment $[9,13]$. Our hypothesis is that patients' digestive ducts remain swollen, which affects the absorption of TLV and results in various plasma concentrations of the drug, accounting for the various clinical effects we see in patients with ADHF even though they have all been given the same dose of TLV.

\section{Change in the plasma TLV concentration over a 7-day treatment}

In our study patients, the plasma TLV concentration was $67.6 \pm 30.1 \mathrm{ng} / \mathrm{mL}$ on day $1,98.3 \pm$ $\pm 39.6 \mathrm{ng} / \mathrm{mL}$ on day 3 , and $144.8 \pm 44.2 \mathrm{ng} / \mathrm{mL}$ on day 7 (Fig. 4). The reported peak plasma concentra- tion of TLV in healthy subjects with no swelling of digestive ducts was $135 \pm 53 \mathrm{ng} / \mathrm{mL}$ after oral administration of $7.5 \mathrm{mg}$ TLV [11]. This concentration was higher than concentrations in our study patients, probably because of the higher dose of TLV administered and the absence of digestive system swelling. The previously reported plasma concentration of TLV in patients with decompensated heart failure was $92.47 \pm 53.58 \mathrm{ng} / \mathrm{mL}$ on day 1 $4 \mathrm{~h}$ after oral administration of $7.5 \mathrm{mg}$ TLV and $126.04 \pm 40.90 \mathrm{ng} / \mathrm{mL}$ on day 7 [10]. The plasma concentration on day 1 was higher than that in our patients probably because there was no evidence of fluid overload in the previously reported patients. 


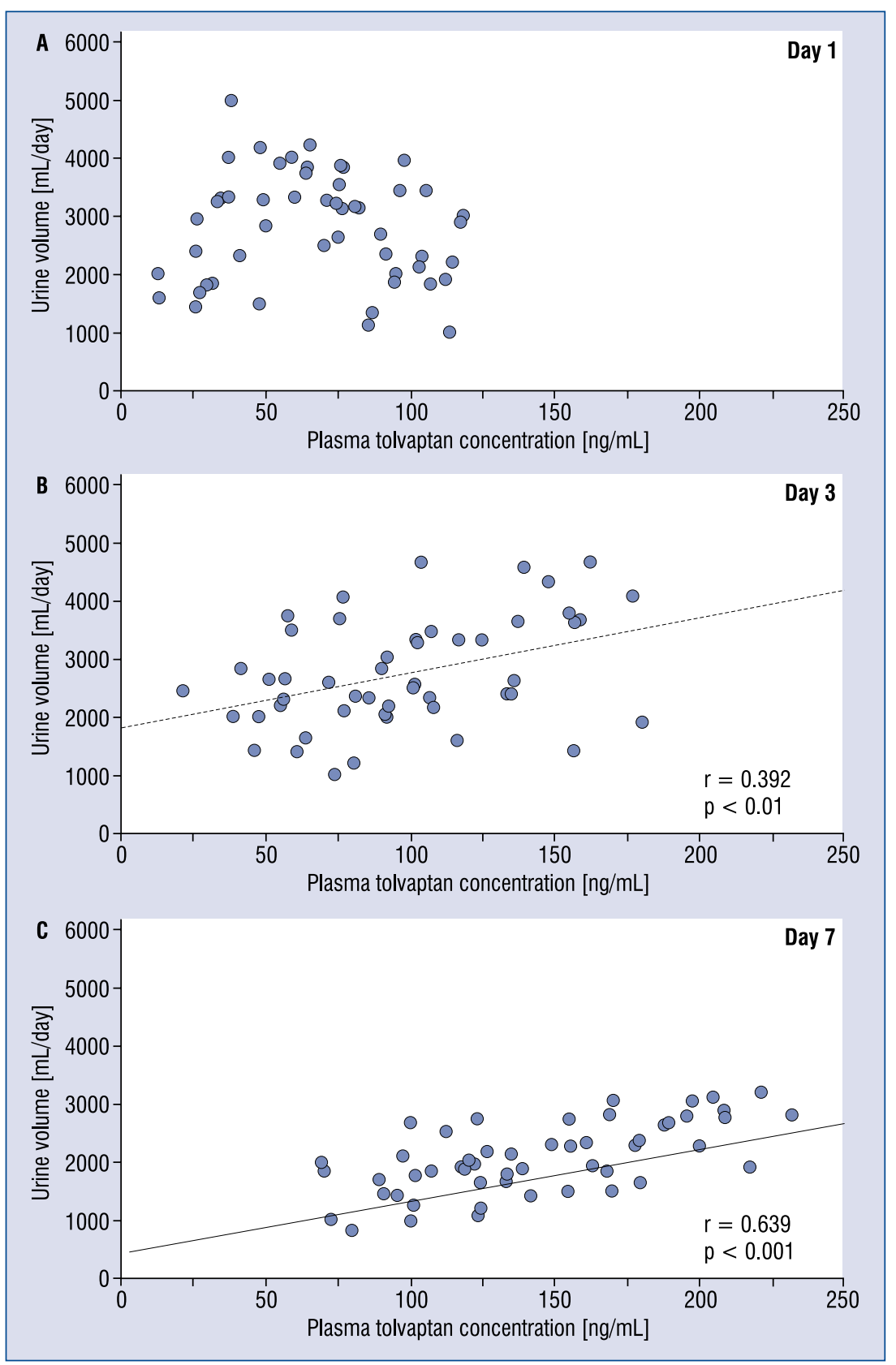

Figure 5. Relations between the urine volume and plasma tolvaptan concentration on day 1 (A), day 3 (B) and day 7 (C). No relation was observed on day 1 , but correlation was noted on day $3(r=0.392, p<0.01)$ and day 7 ( $r=0.639$, $\mathrm{p}<0.001)$.

The plasma TLV concentration on day 7 was lower than that in our patients because digestive system swelling in our patients was greatly reduced by the intensive diuretic therapy. The change in mean body weight of the previously reported patients over 7 days $(-1.5 \mathrm{~kg})$ was less than that of our patients $(-5.5 \mathrm{~kg})$. Due to the fact that there was little change in serum osmolality of our patients (from $288.9 \pm 11.5 \mathrm{mOsm} / \mathrm{kg} \times \mathrm{H}_{2} \mathrm{O}$ on day 0 to $291.5 \pm 10.5 \mathrm{mOsm} / \mathrm{kg} \times \mathrm{H}_{2} \mathrm{O}$ on day 1 to $291.69 \pm$ $\pm 7.0 \mathrm{mOsm} / \mathrm{kg} \times \mathrm{H}_{2} \mathrm{O}$ on day 3 and $288.7 \pm 8.6 \mathrm{mOsm} /$ $/ \mathrm{kg} \times \mathrm{H}_{2} \mathrm{O}$ on day 7 ), hemoconcentration was not seen in our patients. Thus, the increase in the plasma TLV concentration can be explained by improved absorbance due to the reduced digestive system swelling achieved with diuretic administration. 


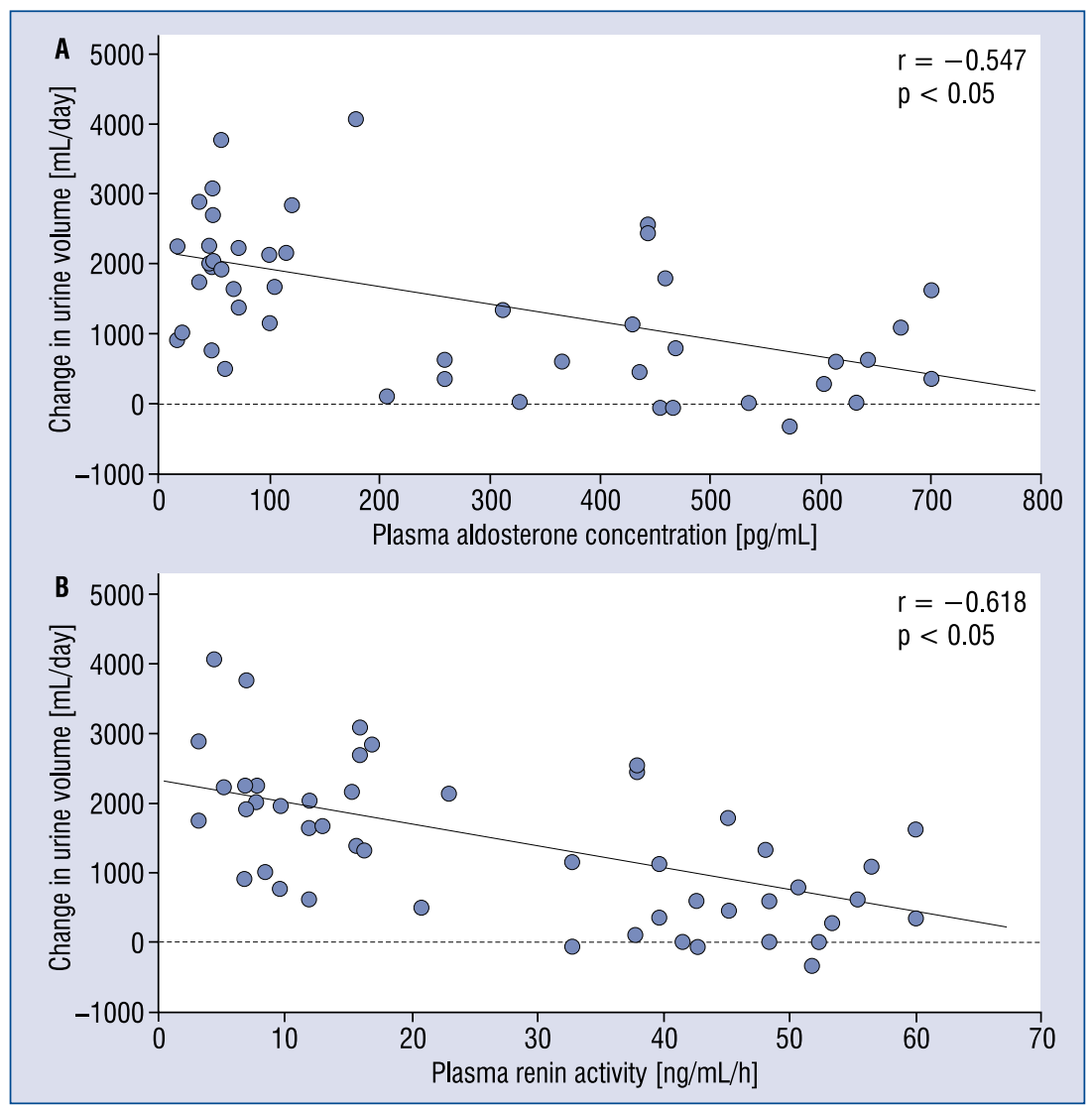

Figure 6. Relations between urine volume and plasma aldosterone concentration (PAC) (A) and plasma renin activity (PRA) (B) on day 1. Urine volume after addition of tolvaptan correlated inversely with $\mathrm{PAC}(r=-0.547, p<0.05)$ and PRA $(r=-0.618, p<0.05)$.

\section{RAAS activity and the clinical effect of TLV during early phase treatment}

In the late phase of treatment (days 3 and 7) for ADHF, the clinical effect of TLV was shown to correlate with the plasma concentration of TLV. This was not true during the early phase of treatment (day 1), and then PRA and PAC correlated inversely with the change in urine volume. Neurohumoral factors including RAAS factors increase fluid retention [17]. Angiotensin-II, in particular, increases vasopressin, which weakens the effect of TLV somewhat, and aldosterone, which is the final product of the RAAS, increases retention of sodium and water in the renal tubules and is thus thought to act against the effects of TLV [18-20]. Neither carperitide nor any inotropic agent that would enhance RAAS activity in patients with ADHF was used in this study. Therefore, RAAS activity, which is usually observed in patients with ADHF even though they have been given RAAS inhibitors, probably inhibited the effect of TLV. It is natural to assume that inhibition of the RAAS in the early phase of treatment for ADHF enhances the clinical effects of TLV, despite previously reported negative results of standard diuretic therapy [21-24]. Futher investigations of relationship between clinical effect of TLV and medications which affect the RAAS activities are warranted.

\section{Safety of routine use of low-dose TLV in early phase treatment}

Some clinical investigators have reported the safety and efficacy of immediate use of TLV for ADHF $[9,13]$. In our study, we used $7.5 \mathrm{mg}$ of TLV during the early phase of treatment for 92 decompensated heart failure patients who showed fluid overload after intravenous administration of $40 \mathrm{mg}$ furosemide. Adverse effects were observed in 4 patients, i.e. hypernatremia (serum sodium $>146 \mathrm{mEq} / \mathrm{mL}$ ), but none of them had clinical symptoms of hypernatremia. In addition, we withdrew from administering TLV in 36 patients due to the disappearance of evidence of fluid overload in fewer than 7 days. Thus, we believe $7.5 \mathrm{mg}$ TLV can be used safely and effectively in the early phase of 
treatment of ADHF patients with fluid overload and whose urine volume is less than $1,500 \mathrm{~mL} /$ day after intravenous administration of $40 \mathrm{mg}$ furosemide.

\section{Limitations of the study}

Limitations of our study that may have influenced applicability of our results are as follows. First, we did not directly observe changes in swelling of digestive ducts or of the absorbance of TLV during the week of TLV administration. Second, it is possible that the RAAS had a confounding effect on the urine volume. Third, we excluded patients with low cardiac output on the basis of hypotension rather than invasive measurement of cardiac output. For these reasons, our study findings need to be further explored.

\section{Conclusions}

In this clinical study, we found that the plasma TLV concentration increased during treatment and correlated with the clinical effects in the late phase of treatment but not in the early phase, which suggested that the effect of TLV has a possibility to be inhibited by RAAS activity.

\section{Conflict of interest: None declared}

\section{References}

1. Gheorghiade M, Niazi I, Ouyang J et al. Tolvaptan Investigators: Vasopressin V2-receptor blockade with tolvaptan in patients with chronic heart failure: Results from a double-blind, randomized trial. Circulation, 2003; 107: 2690-2696.

2. Gheorghiade M, Gattis WA, O'Connor CM et al. Acute and Chronic Therapeutic Impact of a Vasopressin Antagonist in Congestive Heart Failure (ACTIV in CHF) Investigators: Effects of tolvaptan, a vasopressin antagonist, in patients hospitalized with worsening heart failure: A randomized controlled trial. JAMA, 2004; 291: 1963-1971.

3. Gheorghiade M, Konstam MA, Burnett JC Jr et al. Efficacy of Vasopressin Antagonism in Heart Failure Outcome Study With Tolvaptan (EVEREST) Investigators: Short-term clinical effects of tolvaptan, an oral vasopressin antagonist, in patients hospitalized for heart failure: The EVEREST Clinical Status Trials. JAMA, 2007; 297: 1332-1343.

4. Udelson JE, Orlandi C, Ouyang J et al. Acute hemodynamic effects of tolvaptan, a vasopressin V2 receptor blocker, in patients with symptomatic heart failure and systolic dysfunction: An international, multicenter, randomized, placebo-controlled trial. J Am Coll Cardiol, 2008: 52: 1540-1545.

5. Matsuzaki M, Hori M, Izumi T, Asanoi H, Tsutamoto T. Tolvaptan Investigators: Effects of tolvaptan on volume overload in Japanese patients with heart failure: Results of a phase II, multicenter, randomized, double-blind, placebo-controlled, parallelgroup study. Cardiovasc Drugs Ther, 2011; 25 (suppl. 1):S19-S31.

6. Matsuzaki M, Hori M, Izumi T, Fukunami M. Tolvaptan Investigators: Efficacy and safety of tolvaptan in heart failure patients with volume overload despite the standard treatment with conventional diuretics: A phase III, randomized, double-blind, placebo-controlled study (QUEST study). Cardiovasc Drugs Ther, 2011; 25 (suppl. 1): S33-S45.
7. Watanabe K, Dohi K, Sugimoto T et al. Short-term effects of low-dose tolvaptan on hemodynamic parameters in patients with chronic heart failure. J Cardiol, 2012; 60: 462-469.

8. Suzuki S, Yoshihisa A, Yamaki T et al. AVCMA investigators: Acute heart failure volume control multicenter randomized (AVCMA) trial: Comparison of tolvaptan and carperitide. J Clin Pharmacol, 2013: 53: 1277-1285.

9. Shirakabe A, Hata N, Yamamoto $\mathrm{M}$ et al. Immediate administration of tolvaptan prevents the exacerbation of acute kidney injury and improves the mid-term prognosis of patients with severely decompensated acute heart failure. Circ J, 2014; 78: 911-921.

10. Inomata T, Izumi T, Matsuzaki M, Hori M, Hirayama A. Tolvaptan Investigators: Phase III clinical pharmacology study of tolvaptan. Cardiovasc Drugs Ther, 2011; 25 (suppl. 1): S57-S65.

11. Kim SR, Hasunuma T, Sato O, Okada T, Kondo M, Azuma J. Pharmacokinetics, pharmacodynamics and safety of tolvaptan, a novel, oral, selective nonpeptide AVP V2-receptor antagonist: Results of single- and multiple-dose studies in healthy Japanese male volunteers. Cardiovasc Drugs Ther, 2011; 25 (suppl. 1): S5-S17.

12. Hauptman PJ, Burnett J, Gheorghiade M et al. Clinical course of patients with hyponatremia and decompensated systolic heart failure and the effect of vasopressin receptor antagonism with tolvaptan. J Card Fail, 2013; 19: 390-397.

13. Dohi K, Ito M. Immediate and short-term use of tolvaptan for acute decompensated heart failure. Circ J, 2014; 78: 829-831.

14. Vaduganathan M, Gheorghiade M, Pang PS et al. Efficacy of oral tolvaptan in acute heart failure patients with hypotension and renal impairment. J Cardiovasc Med (Hagerstown), 2012; 13: 415-422.

15. Matsue Y, Suzuki M, Seya M et al. Tolvaptan reduces the risk of worsening renal function in patients with acute decompensated heart failure in high-risk population. J Cardiol, 2013; 61: 169-174.

16. Imamura $\mathrm{T}$, Kinugawa $\mathrm{K}$, Shiga $\mathrm{T}$ et al. Novel criteria of urine osmolality effectively predict response to tolvaptan in decompensated heart failure patients-association between non-responders and chronic kidney disease. Circ J, 2013; 77: 397-404.

17. Van Zwieten PA. Compensatory changes of sympathetic tone, the renin-angiotensin-aldosterone system, vasopressin, and ANF as potential therapeutic targets in congestive heart failure. $Z$ Kardiol, 1988; 77 (suppl. 5): 67-76.

18. Creager MA, Faxon DP, Cutler SS, Kohlmann O, Ryan TJ, Gavras H. Contribution of vasopressin to vasoconstriction in patients with congestive heart failure: Comparison with the renin-angiotensin system and the sympathetic nervous system. J Am Coll Cardiol, 1986; 7: 758-765.

19. Pedersen EB, Danielsen H, Jensen T, Madsen M, Sørensen SS, Thomsen OO. Angiotensin II, aldosterone and arginine vasopressin in plasma in congestive heart failure. Eur J Clin Invest, 1986; 16: $56-60$.

20. Nicholls MG, Espiner EA, Hughes H, Rogers T. Effect of potassium-sparing diuretics on the renin-angiotensin-aldosterone system and potassium retention in heart failure. Br Heart J, 1976; 38: 1025-1030.

21. Clair MJ, King MK, Goldberg AT et al. Selective vasopressin, angiotensin II, or dual receptor blockade with developing congestive heart failure. J Pharmacol Exp Ther, 2000; 293: 852-860.

22. Waanders F, Vaidya VS, van Goor $\mathrm{H}$ et al. Effect of renin-angiotensin-aldosterone system inhibition, dietary sodium restriction, and/or diuretics on urinary kidney injury molecule 1 excretion in nondiabetic proteinuric kidney disease: A post hoc analysis of a randomized controlled trial. Am J Kidney Dis, 2009; 53: $16-25$.

23. Slagman MC, Navis G, Laverman GD. Reversible effects of diuretics added to renin-angiotensin-aldosterone system blockade: Impact on interpretation of long-term kidney function outcome. Am J Kidney Dis, 2010; 56: 601-602.

24. Parthasarathy HK, Alhashmi K, McMahon AD et al. Does the ratio of serum aldosterone to plasma renin activity predict the efficacy of diuretics in hypertension? Results of RENALDO. J Hypertens, 2010; 28: 170-177. 